\title{
Percepção da população local sobre o fenômeno turístico: análises e reflexões (Teresina- PI)
}

\section{Perception of the local population about the tourist phenomenon: analysis and reflection (Teresina PI)}

\section{La percepción de la población local sobre el fenómeno turístico: el análisis y la reflexión (Teresina PI)}

\author{
Erminia Medeiro Macedo ${ }^{1}$
}

\section{Andréia Magalhães Rocha ${ }^{2}$}

Resumo: O presente estudo lança o olhar sobre a relação que se estabelece entre a população inserida no contexto da atividade turística no município de Teresina-PI. Pretende-se, assim, analisar a percepção da população local sobre o turismo em Teresina e identificar os efeitos dessa atitude. Esta análise é derivada de uma pesquisa monográfica, possui abordagem qualitativa e objetivo descritivo, enquadrando-se no estudo de caso. Para o seu desenvolvimento, foram aplicados questionários com cento e vinte teresinenses e residentes na cidade. Os aspectos conclusivos desta investigação permitem concluir que a maior parte da população pesquisada não reconhece o turismo enquanto atividade socioeconômica na cidade de Teresina. Ademais, os entrevistados também demonstraram desconhecimento acerca dos elementos constitutivos de um destino turístico e incerteza sobre o seu papel no desenvolvimento turístico local. Destarte, espera-se que essa análise contribua para incitar a ampliação do debate sobre a prática do turismo em Teresina, fortalecendo, assim, o seu posicionamento enquanto destino turístico no mercado nacional.

Palavras-chave: Turismo; Reconhecimento; População.

Abstract: The present study sheds on the relationship between the population within the context of the tourist activity in the city of Teresina-PI. It is intended, therefore, to analyse the perception of local people about tourism in Teresina and identify the effects of this attitude. This analysis is derived from a monographic research, has a qualitative approach and descriptive, objective framing in the case study. For its development, questionnaires were applied with teresinenses and 120 residents in the city. The conclusive aspects of this investigation lead to the conclusion that the majority of the population surveyed does not recognize tourism as economic activity in the city of Teresina. Furthermore, respondents also showed ignorance about the constituent elements of a tourist destination and uncertainty about its role in the local tourism development. Thus, it is expected that this review will contribute to encourage the expansion of the debate about the practice of tourism in Teresina, strengthening their position as a tourist destination in the national market.

Keywords: Local Perception; Tourist destination; Teresina.

\footnotetext{
${ }^{1}$ Mestre em Turismo pela UNB- Universidade de Brasília. Email: erminia.medeiros@hotmail.com

${ }^{2}$ UFRN. Email: andreiamdr@ hotmail.com
} 
Resumen: El presente estudio arroja sobre la relación entre la población en el contexto de la actividad turística en la ciudad de Teresina-PI. Se pretende analizar la percepción de la población local sobre el turismo en Teresina e identificar los efectos de esta actitud. Este análisis se deriva de una investigación monográfica, tiene un enfoque cualitativo y descriptivo, objetivo enmarcado en el estudio de caso. Para su desarrollo, se aplicaron cuestionarios con teresinenses y 120 residentes en la ciudad. Los aspectos concluyentes de esta investigación llevan a la conclusión que la mayoría de la población encuestada no reconoce el turismo como actividad económica en la ciudad de Teresina. Además, los encuestados demostraron falta de conocimiento acerca de los elementos constitutivos de un destino turístico y la incertidumbre sobre su papel en el desarrollo del turismo local. Por lo tanto, se espera que este informe contribuirá a fomentar la expansión del debate sobre la práctica del turismo de Teresina, fortaleciendo su posición como destino turístico en el mercado nacional.

Palabras clave: Percepción local; Destino turístico; Teresina.

\section{Introdução}

Considerando que o turismo é uma atividade contemporânea de cunho social e econômico, é importante considerar que o mesmo é responsável por potencializar e incrementar a dinâmica local. Neste contexto, torna-se essencial que, no processo de desenvolvimento turístico em uma localidade, a população se identifique e participe ativamente, colaborando e compreendendo os impactos causados em seu cotidiano. De acordo com Beni (2006, p. 44) “[...] o turismo é um meio de desenvolvimento suscetível de fazer progredir os povos e as nações", por esse motivo julga-se importante a participação da população local no processo e (re) conhecimento e desenvolvimento da potencialidade de sua região.

Segundo o Ministério do Turismo, a cidade de Teresina é considerada um destino indutor do turismo nacional por ser a capital e também o principal portão de entrada do estado do Piauí. Na última década muitas mudanças ocorreram no que se refere à gestão do turismo local, que foi incorporado à Secretaria Municipal de Desenvolvimento Econômico e Turismo - SEMDEC, fato que contribuiu para uma ampliação dos investimentos e melhorias na oferta turística, especialmente no setor de alimentos e bebidas, entretenimento e hotelaria.

No entanto, apesar desses avanços, observações empíricas apontam que a população teresinense não se mostra engajada com o turismo, denotando uma falta de conhecimento e reconhecimento desta atividade no âmbito local. Este contexto motivou a realização de um estudo que buscasse responder a seguinte problemática: Qual a percepção da população local sobre o turismo em Teresina-PI? 
O presente artigo é derivado de um trabalho monográfico, possui abordagem qualitativa e objetivo descritivo, enquadrado como estudo de caso. Tem como principal objetivo analisar a percepção da população local sobre o turismo em Teresina e identificar os efeitos dessa atitude. Dito de outra forma, propõe-se a investigar aspectos fundamentalmente relevantes para a análise, como os significados, motivos, crenças, e atitudes dos sujeitos quanto à prática da atividade turística (MINAYO, 200).

Para o desenvolvimento deste estudo, realizou-se em um primeiro momento levantamento bibliográfico (em livros, sites oficiais, leis, documentos e artigos científicos) a fim de garantir o embasamento teórico e sistemático, para facilitar a compreensão do fato abordado. No segundo momento foram visitados os órgãos públicos SETUR, PIEMTUR, FMC, FUNDAC CEPRO e Prefeitura de Teresina, a fim de buscar informações oficiais sobre a gestão pública do turismo em Teresina. A partir dessas informações, foram selecionados os principais atrativos turísticos naturais, culturais e artificiais da cidade, considerados componentes do produto turístico, utilizando como critério aqueles que fossem dotados de melhor estrutura receptiva para o turismo como: acesso, sinalização e informação turística. Posteriormente, foi desenvolvida a pesquisa de campo.

A pesquisa de campo se desenvolveu a partir da utilização de questionário contendo um número de 11 (onze) perguntas fechadas e semiabertas e um universo total de 120 (cento e vinte) pessoas. É importante destacar que do total de perguntas realizadas, foram elencados os cinco aspectos mais relevantes para a temática desenvolvida. Para participar da pesquisa, era necessário ser teresinense e residir na cidade. Os questionários foram aplicados no bairro centro, onde podem ser encontradas pessoas oriundas de todos os bairros de Teresina, no período de 26 de Janeiro a 9 de Fevereiro de 2011.

Os dados coletados foram analisados por meio da técnica de amostragem que, segundo Appolinário (2004), permite obter um parâmetro de pesquisa que consiga agregar valor aos dados obtidos. Para que a amostra não fosse comprometida em relação a determinado fator ou sofresse alguma predisposição de preferência por parte do pesquisador, utilizou-se a técnica da observação, que, “[...] não consiste apenas em ver e ouvir, mas também em examinar fatos ou fenômenos que se deseja estudar”. (LAKATOS, 2004, p. 275).

Espera-se que, os resultados desta análise possibilitem ampliar a discussão desta temática, fornecendo elementos que auxiliem no processo de elaboração de um novo planejamento 
turístico para a cidade de Teresina, garantindo a inclusão e efetiva participação da sua população em todas as fases, para, com isso, colaborar com o fortalecimento da autoestima e identidade local através do turismo.

O trabalho está estruturado em três seções. A primeira apresenta os aspectos que identificam e constituem um destino turístico. A segunda introduz uma breve análise estrutural do turismo na cidade de Teresina, com sua caracterização socioeconômica e turística e a terceira analisa a percepção da população local sobre o turismo em Teresina, a partir da apresentação e discussão dos dados coletados.

\section{A Construção de um Destino Turístico}

O estudo de um destino turístico se torna um dos aspectos mais importantes para a compreensão da atividade turística em uma região, pois é nele que a demanda encontra elementos motivacionais para o seu deslocamento e usufruto dos atrativos e serviços turísticos disponíveis. Assim, um destino turístico caracteriza-se por apresentar uma infraestrutura adequada, equipamentos e serviços específicos, profissionais capacitados e recursos naturais e culturais com atratividade suficiente para captar uma demanda significativa. A demanda, por sua vez, tem características singulares e se constitui em uma força impulsionadora para o desenvolvimento do turismo em uma localidade.

Os destinos turísticos são considerados estruturas urbanas construídas a partir do seu aparato sociocultural, capazes de propiciar melhor qualidade de vida aos consumidores internos e externos, que são os visitantes e turistas que buscam desfrutar da sua oferta turística. Toda essa dinâmica produz e fomenta o desenvolvimento econômico local, promovendo benefícios mútuos (VALSS, 2006).

A cidade de Teresina, objeto de estudo desta pesquisa não apresenta, em sua totalidade, as características de um destino turístico, porém possui uma vocação para a prática da atividade, através dos seus recursos naturais e seu patrimônio cultural, que são, até certo ponto, pouco explorados, conforme se verá no decorrer deste trabalho.

Para Valls (2006), as funções que representam os destinos turísticos estão relacionadas com quatro objetivos apresentados na figura seguinte: 


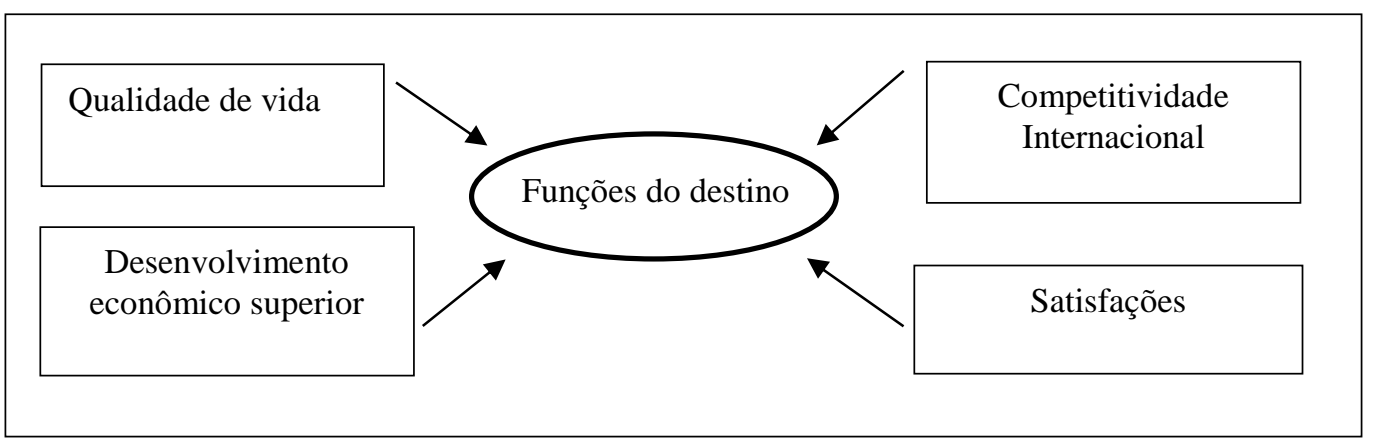

Figura 1 - Funções do destino turístico

Fonte: Valls, 2006.

A partir da análise da figura, pode-se entender que a qualidade de vida da população local de um destino turístico está atrelada ao desenvolvimento da região nas esferas social, econômica e ecológica, aumentando a competitividade por oferecer uma estrutura integrada e concisa da oferta, a partir dos serviços oferecidos, resultando em satisfação para os próprios residentes como para a demanda que se sente atraída.

Dias (2005, p. 75) destaca que “[...] uma destinação turística pode ser considerada uma localidade, uma região ou um país que recebe visitantes que para lá se dirigem para passar um período relativamente curto". Nesta perspectiva, as cidades se constituem enquanto principais destinos dos fluxos turísticos, pois elas se tornam referência de estrutura, apoio e deslocamentos de turistas. Dessa maneira, pode-se dizer que o destino turístico é similar a uma empresa, tendo os turistas como seus principais clientes, além de uma variedade enorme de equipamentos, recursos e materiais a serem disponibilizados aos mesmos.

No entanto, desenvolver a atividade turística em uma localidade e transformá-la em um destino turístico é uma tarefa complexa, pois, depende de uma série de aspectos indispensáveis na sua construção, despertando inicialmente o interesse pelo destino, já que de nada adianta compor-se de um significativo potencial para o turismo sem que os gestores públicos e a população local atentem para a promoção e inserção da atividade no município, através de investimentos, bem como do comportamento responsável praticado por todos os agentes sociais envolvidos. Assim, a comunidade autóctone é uma parte primordial para o crescimento do turismo local, a partir do seu engajamento na tomada de decisões, impulsionando a produção de valores internos por meio do reconhecimento de seus atrativos. 
Para ser condescendente com a realidade vivenciada localmente, o exercício da atividade turística requer um planejamento contínuo nas áreas específicas em que essa prática acontece. Assim, sendo o planejamento turístico é essencial na estruturação de um destino, Boullón (2002, p. 72), diz que "[...] sua finalidade é o ordenamento das ações do homem sobre o território, e ocupa-se em resolver harmonicamente a construção de todo tipo de coisas, bem como em antecipar o efeito da exploração dos recursos naturais".

A partir das considerações do autor, depreende-se que o planejamento turístico é benéfico em todas as suas instâncias, pois o mesmo tem a função de conjugar a dinâmica da atividade turística com a adequação desta na localidade receptora, ou seja, o planejamento tem a capacidade de ordenamento, através das etapas necessárias, do uso sustentável dos recursos naturais, culturais e sociais disponíveis.

Assim, segundo Ruschmann (1997, p. 100), “[...] o reconhecimento da amplitude de fenômeno e a abrangência dos fatores, além de caráter interdisciplinar e convergente da atividade, tornaram imprescindível o planejamento integrado nas localidades receptoras". Neste sentido, o processo de construção de um destino turístico postula um planejamento eficaz, participativo e inclusivo. Em relação à cidade de Teresina, a gestão planejada do turismo é recente, conforme será visto na discussão subsequente.

\section{Análise Estrutural do Turismo na Cidade de Teresina}

A cidade de Teresina foi fundada em 1852 é acidade mais populosa do Estado do Piauí, com 840.600 mil habitantes (IBGE, 2015). Localiza-se no Centro-Norte Piauiense a 366 km do litoral, sendo, portanto, a única capital da região Nordeste que não é banhada pelo mar.

Em relação ao seu aspecto urbanístico, Learth (2011) ressalta que a cidade de Teresina se apresenta como um polo de atração populacional por apresentar serviços de saúde e educação de qualidade, além de possuir adequada infraestrutura urbana, viária, e habitacional local. Desde sua fundação, apresenta, portanto, um crescimento contínuo, progressivo, acelerado e desigual. Segundo a Prefeitura Municipal de Teresina (2010), a cidade não apresenta características típicas de uma cidade turística, porém configura-se como uma cidade ideal para a realização de eventos de diversas naturezas.

De acordo com a Secretaria Municipal de Desenvolvimento Econômico e Turismo SEMDEC (2015), a cidade possui 138 auditórios com capacidade total para 13.925 (treze mil, 
novecentos e vinte e cinco) lugares, porém não possui um auditório com capacidade para 28.241 (vinte e oito mil, duzentos e quarenta e um mil) lugares o que dificulta a captação de maiores eventos, já que a mesma possui uma boa estrutura de hospedagem, representada numericamente em 85 meios de hospedagem, totalizando 4.485 (quatro mil, quatrocentos e oitenta e cinco mil) leitos disponíveis.

Em se tratando de atrativos turísticos naturais em Teresina, destacam-se o Parque Ambiental Encontro dos Rios e os rios Poty e Parnaíba. No aspecto cultural, a ênfase é dada ao Polo Cerâmico do Poty Velho e a Praça Pedro II, devido ao seu entorno que abrange uma série de outros atrativos de grande importância, como o Theatro4 de setembro, o Clube dos Diários e a Central de Artesanato Mestre Dezinho. Outro importante atrativo é a Ponte Estaiada, que possui um mirante de 95 metros de altura com dois elevadores panorâmicos em área de 125 metros quadrados, sendo a única edificação do continente Americano que possui um mirante fixado em um mastro central (Jornal O Dia. Teresina, 30.03.2010). A gastronomia, por sua vez, se revela através dos pratos mais conhecidos, a galinha cabidela, ou galinha caipira e o capote ao molho.

Um dos grandes avanços do turismo em Teresina deu-se primeiramente com a criação da Secretaria de Estado do Turismo do Piauí - SETUR, em 2007, que, dentre outras atribuições, nasceu com a finalidade de fomentar o turismo regional, investindo na qualificação e profissionalização do setor, estimulando novos empreendimentos e promovendo o planejamento da infraestrutura turística no estado como um todo e principalmente na capital, que é um dos principais portões de entrada para os demais destinos turísticos do Piauí (PIEMTUR, 2010).

Paralelo à criação da SETUR surgiu a Secretaria Municipal de Desenvolvimento Econômico e Turismo - SEMDEC, através da Coordenação Especial de Turismo que tem, em sua concepção, a necessidade de estimular e acompanhar os processos turísticos de âmbito municipal. Ademais, tem a função específica de desenvolver o turismo local, por meio das potencialidades existentes, transformando assim, estes recursos turísticos em atrativos, e, assim, compor um produto capaz de promover o fluxo constante de visitantes à cidade. Não obstante o turismo na cidade de Teresina ter recebido investimentos do setor público e privado na última década, é necessário sua inclusão na agenda governamental, elevando-o a uma política pública promotora de desenvolvimento socioeconômico local. 


\section{Análise dos Resultados}

O perfil dos entrevistados apresenta, de forma majoritária as seguintes características: trinta e seis por cento (36\%) possui nível superior incompleto; quarenta e sete por cento (47\%) apresentam faixa etária entre 18 e 26 anos; cinquenta e um por cento (51\%) com uma renda que varia de 01 a 03 salários mínimos. É importante destacar que do total de 11 (onze) perguntas realizadas, foram elencados os cinco aspectos mais relevantes para a temática desenvolvida, apresentados a seguir.

Em relação ao questionamento da existência do turismo na cidade de Teresina, o resultado mostra que há uma diferença mínima, quase irrelevante, entre os que concordam e os que discordam. Todavia, a maioria das respostas observadas no gráfico abaixo apontou o aspecto negativo, o que corresponde a cinquenta e um por cento (51\%), ou seja, a população local não reconhece a prática da atividade turística em Teresina.
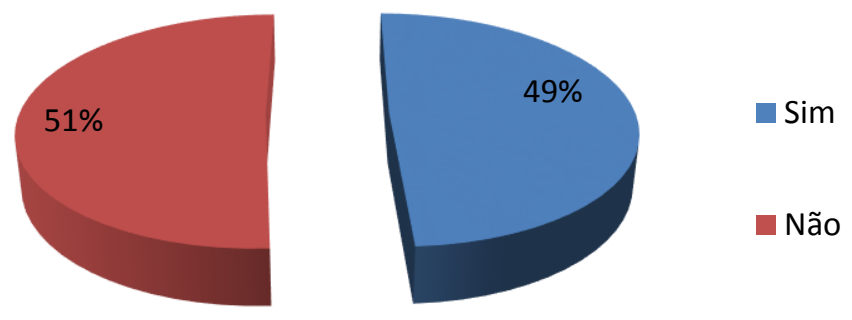

Gráfico 1 - Existência do turismo em Teresina-PI

Fonte: Pesquisa direta, 2011.

Acredita-se que, para os moradores da cidade, a inexistência da atividade turística está atrelada a alguns fatores que poderiam ajudar a incrementar o setor local, sendo necessária uma mudança no cenário atual, como podemos constatar nas observações feitas pelos entrevistados que responderam negativamente:

- "Poucos investimentos governamentais em infraestrutura, segurança, saúde e educação";

- "Teresina não possui atrativos capazes de motivar uma demanda turística";

- “Teresina não é desenvolvida o suficiente para que a prática do turismo seja possível”.

Para eles, a prática do turismo na cidade só poderá acontecer a partir de um investimento consistente em infraestrutura, segurança, saúde e educação, elementos que, sem dúvida, são imprescindíveis na composição de um destino turístico. 
Quando se considera a indicação da cidade de Teresina como um destino turístico, percebe-se que a propensão dos respondentes demonstrou um aspecto positivo, representada por cinquenta e um por cento (51\%)conforme pode ser observado no gráfico abaixo, opondo-se à pergunta anterior, constituindo-se, portanto, em uma contradição, passível de uma crítica transformadora do aspecto em questão.
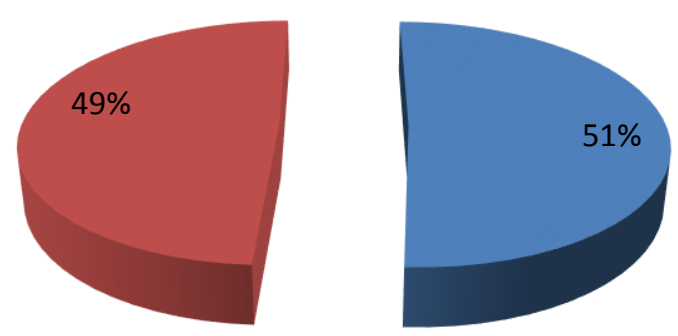

$$
\begin{aligned}
& \text { - Sim } \\
& \text { —ão }
\end{aligned}
$$

Gráfico 2- Indicação de Teresina como destino turístico

Fonte: Pesquisa direta, 2011.

Questionados sobre o porquê da indicação, detectou-se o seguinte resultado:

- "Para chamar a atenção dos políticos";

- "É uma cidade bonita, grande o que com certeza se tivesse mais interesse em criar campos turísticos e lazer de família seria mais frequentada";

- "Possui belezas naturais, comidas típicas de ótima qualidade e proximidade com pontos turísticos do Estado";

As respostas apresentadas mostram um comportamento favorável ao desenvolvimento da atividade turística em Teresina que, segundo os participantes, possui características importantes como atrativos turísticos, muitos lugares não explorados, artesanato, parques ambientais, população receptiva, cidade planejada e diversos serviços de apoio, como, bares, hotéis e restaurantes. Assim, para o público pesquisado, Teresina está apta ao desenvolvimento do setor turístico. Os contrários à indicação da cidade como destino turístico elencaram os seguintes fatores:

- "A cidade é atrasada";

- "Porque não tem nada que possa considerar turístico";

- "Porque além de ter poucos atrativos turísticos, a mesma não possui estrutura física adequada, para receber os turistas". 
Observa-se, portanto, que a situação apresentada mostra uma abordagem hostil por parte de alguns dos questionados, que evidenciam os diversos problemas estruturais e administrativos existentes em Teresina na intenção de promover investimentos no setor turístico e o planejamento para envolver a população teresinense no processo de identificação dos atrativos existentes no âmbito municipal. Destarte, é visível a necessidade de maiores investimentos para a área, cujos benefícios alcançam as esferas social, econômica e ambiental da cidade.

Algumas respostas apresentadas pelos participantes abordaram aspectos elementares como, por exemplo, "para chamar a atenção dos políticos", "para incentivar o crescimento do setor"; outros, de uma forma invasiva, foram enfáticos ao dizer que "a cidade é atrasada", "não possui atrativos turísticos”, “o que há na cidade não empolga os turistas”. Essas considerações demonstram a fragilidade do conhecimento dos pesquisados sobre a composição do destino turístico.

É importante observar que a população se apresenta de forma dividida demonstrando aspectos extremos, ou seja, enquanto alguns concordam com a presença de atrativos turísticos locais, outros dizem que Teresina não possui uma oferta consistente capaz de promover a captação de demanda para a região.

No que tange à dificuldade de acesso aos atrativos turísticos, observa-se que a maioria dos participantes não tem esse problema, pois entende que em sua maioria, possuem uma boa localização, com exceção do Parque Ambiental Encontro dos Rios, Polo Cerâmico do Poty Velho, Ponte Estaiada Mestre João Isidoro França e o Parque Ambiental Zoobotânico que estão mais afastados e o número do transporte público é reduzido.

O gráfico abaixo mostra que setenta e dois por cento (72\%) afirmam não ter dificuldade de acesso, seguidos de vinte e oito por cento (28\%) que afirmam ter dificuldade, talvez por não possuírem transporte próprio, uma aparente dificuldade para a apreciação dos atrativos turísticos supracitados, já que os demais se localizam no centro de Teresina.

Para os teresinenses, o que falta muitas vezes, é a divulgação desses atrativos por parte do poder público, que deveria se posicionar e incrementar a utilidade desses espaços para o lazer e o consequente envolvimento dos moradores na manutenção de sua cultura e história. 


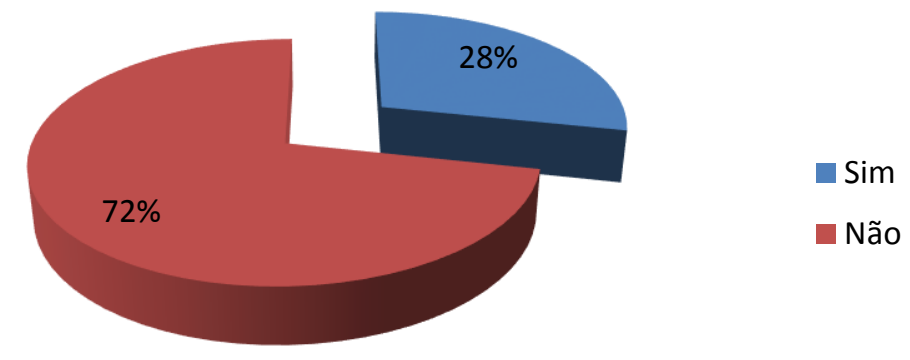

Gráfico 3 - Dificuldade de acesso aos atrativos

Fonte: Pesquisa direta, 2011.

No gráfico abaixo os entrevistados apontam aqueles que são considerados os principais atrativos de Teresina: 35\% afirmaram ser o Parque Ambiental Encontro dos Rios; $25 \%$ indicaram a Central de artesanato Mestre Dezinho; 15\% apontaram o Polo Cerâmico do Poty Velho; 13\% mencionaram o Parque Ambiental Zoobotânico; 7\% sinalizaram o Museu do Piauí - Casa Odilon Nunes e, 5\% afirmaram ser a Casa da Cultura.

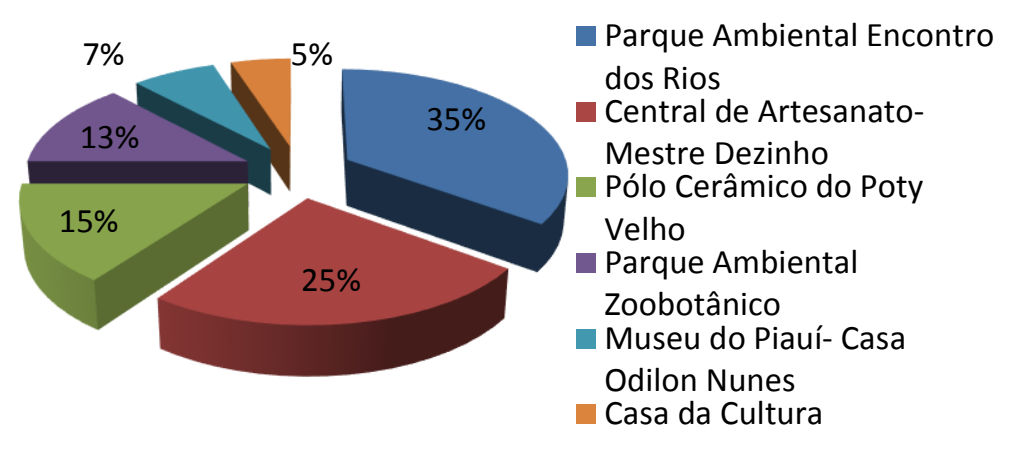

Gráfico 4 - Principais atrativos turísticos de Teresina a partir do olhar da população Fonte: Pesquisa direta, 2011.

Com isso, os resultados indicam que a população (re)conhece a existência de atrativos naturais e culturais na cidade. As características observadas no momento da aplicação dos questionários que motivaram a escolha dos respondentes foram respectivamente: lazer; artesanato e patrimônio cultural. 
Sobre a capacidade de desenvolvimento turístico de Teresina, oitenta e sete por cento $(87 \%)$ afirmaram que a cidade tem potencial para desenvolver a atividade turística, seguida de treze por cento $(13 \%)$ que dizem que a mesma não possui atributos de uma cidade propícia à prática dessa atividade. Conforme pode ser observado no gráfico a seguir.

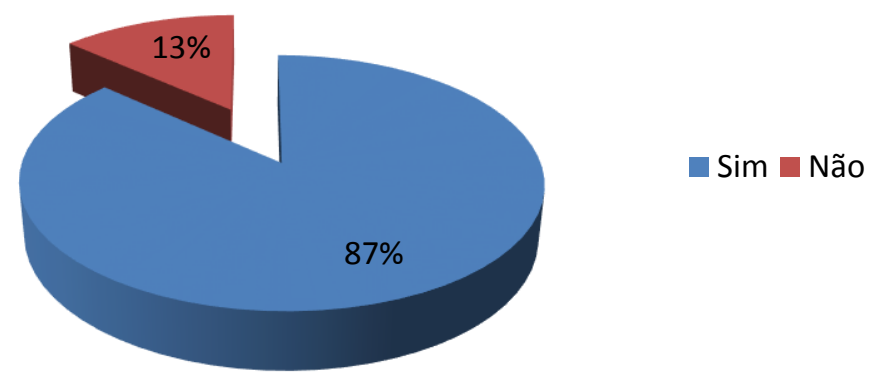

Gráfico 5 - Capacidade local para desenvolvimento do turismo

Fonte: Pesquisa direta, 2011.

Apesar da maioria dos teresinenses declarar que a cidade possui atrativos capazes de gerar demanda turística, muitos apontaram e teceram críticas à ausência de uma estrutura compatível com a realidade vivenciada por outros destinos turísticos consolidados como Belo Horizonte MG, Brasília - DF, Curitiba - PR, entre outros.

Desta forma, percebe-se que os moradores se preocupam com o aspecto estrutural dos atrativos turísticos da cidade, e que a existência dos mesmos por si só não é fator de desenvolvimento para região. É preciso que, atrelado ao atrativo, exista infraestrutura de acesso, sinalização turística, equipamentos de alimentação, lazer, hospedagem, escritório de informações turísticas, profissionais capacitados, etc.

Por fim, a pesquisa mostrou que a cidade de Teresina, na percepção dos residentes, apresenta capacidade para o desenvolvimento da atividade turística pela existência de atrativos naturais, culturais e artificiais, onde estes devem ser dotados de estrutura física e localização adequada, atratividade e acessibilidade. Porém, para que o desenvolvimento dessa atividade ocorra é necessário que os atrativos turísticos locais sejam conhecidos, indicados à apreciação e consequentemente visitados e reconhecidos pela população local. 


\section{Considerações Finais}

Esta investigação buscou analisar como a população local percebe a prática da atividade turística no município de Teresina-PI. Constatou-se que, a maioria dos pesquisados não reconhece a prática da atividade turística na cidade e também não se situam enquanto agentes partícipes do desenvolvimento do destino. Paradoxalmente, estas mesmas pessoas identificam a cidade como um destino turístico, apesar de evidenciarem a dificuldade de informações, o conhecimento e a sua vivência, em relação ao fenômeno turístico e a força de atuação advinda dele, na região em que se apropria.

Assim, esta pesquisa fornece importantes análises que podem subsidiar a gestão pública local do turismo, no sentido de realinhar suas políticas e programas para o setor, de forma que a população teresinense possa participar e se apropriar das ações desenvolvidas, possibilitando, assim, um retorno social coletivo, através da consolidação da atividade na capital, e, individual, com o fortalecimento da identidade local através do turismo.

Diante deste contexto, apontam-se caminhos que possam promover o desenvolvimento da atividade no município de Teresina. Dentre eles, sugere-se destinar ao bacharel em turismo a gestão do turismo local. A atuação de um profissional formado na área é um fator essencial para que a prática do turismo seja efetivada de forma sustentável e consiga aliar as bases fundamentais na gestão participativa e consciente de determinado atrativo. Outro caminho é incluir o turismo na agenda governamental e implementar políticas públicas para o setor; melhorar a estrutura dos atrativos turísticos a fim de que os mesmos ganhem maior visibilidade e, com isso, promovam o incremento do fluxo de visitantes o que consequentemente contribuiria o desenvolvimento do setor.

Entende-se que as sugestões aqui apresentadas são ferramentas necessárias ao melhor direcionamento do planejamento turístico na realidade local, pois incitam um maior envolvimento da população e auxiliam decisivamente o processo de (re) conhecimento de suas potencialidades turísticas locais.

\section{Referências}

APPOLINÁRIO, F. (2004). Dicionário de metodologia científica: Um guia para a produção do conhecimento científico. São Paulo: Atlas.

BENI, M. C. (2006). Política e planejamento de turismo no Brasil. São Paulo: Aleph. 
BOULLÓN, R. C (2002). Planejamento do espaço turístico. Bauru, SP: EDUSC.

DIAS, R. (2005). Introdução ao Turismo. São Paulo: Atlas.

Empresa de Turismo do Piauí S/A. Institucional(2010). Disponível em:〈http://www.piemtur.gov.br/>. Acesso em: 02 nov.2010.

FORTES, R. L. F., coord. (2010). Perfil de Teresina: econômico, social, físico e demográfico. Secretaria Municipal de Desenvolvimento Econômico e Turismo - SEMDEC, Teresina.

IBGE. População estimada (PI). Censo 2014. Disponível em <http://www.cidades.ibge.gov.br/xtras/perfil.php?lang=\&codmun=221100\&search=piaui|teresi na> Acessoem: 04 de mai, 2015.

LAKATOS, E. M.; MARCONI, M. de A. (2004). Técnicas de Pesquisa. 4. ed. - São Paulo: Atlas.

LEARTH, A. (2011). Roteiro Turístico Histórico Cultural "Teresina me Fascina": Uma proposta. Dissertação de Mestrado. CET.- Centro de Excelência em Turismo, Universidade de Brasília.

MINAYO, M. C. S. (Org.). Pesquisa social: teoria, método e criatividade. Petrópolis:Vozes, 2001.

RUSCHMANN, D. V. de M. (1997). Turismo e planejamento sustentável: A proteção do meio ambiente. Campinas, SP: Papirus.

SECRETARIA MUNICIPAL DE DESENVOLVIMENTO ECONÔMICO E TURISMO. Manual de Serviços Turísticos: viver+Teresina. Prefeitura de Teresina, 2015

O DIA. Um novo caminho para atravessar Teresina (2010). Jornal O Dia.Teresina, 30 mar.

VALLS, J. F. (2006). Gestão integral de destinos turísticos sustentáveis. Rio de Janeiro: Editora FGV.

\section{Recebido em: 06/06/2016}

Reavaliado em: 12/09/2016

Aprovado em: 10/11/2016 